\title{
Mixing and convection in the Greenland Sea from a tracer-release experiment
}

A. J. Watson ${ }^{\star}$, M.-J. Messias ${ }^{\star}$, E. Fogelquist $\dagger$, K. A. Van Scoy $\ddagger$, T. Johannessen $§$, K. I. C. Oliver ${ }^{\star}$, D. P. Stevens $\|$, F. Reyg, T. Tanhua $\dagger$, K. A. Olsson $\dagger$, F. Carse ${ }^{\star}$, K. Simonsen\#, J. R. Ledwell ${ }^{1}$, E. Jansen $\$, D. J. Cooper $\ddagger$, J. A. Kruepke $\ddagger$ \& E. Guilyardi ${ }^{\star}$

* School of Environmental Sciences, University of East Anglia, Norwich NR4 7TJ, $U K$

$\dagger$ Department of Analytical and Marine Chemistry, Göteborg University, S-41296, Göteborg, Sweden

$\$$ Atmospheric and Oceanic Sciences, University of Wisconsin-Madison, 1225 West Dayton Street, Madison, Wisconsin 53706, USA

$\$$ University of Bergen, Department of Geology, Allégaten 71, N-5007 Bergen, Norway

II School of Mathematics, University of East Anglia, Norwich NR4 7TJ, UK

9 Institute of Marine Research, Department of Marine Environment,

Postboks 1870-Nordnes, N-5024 Bergen, Norway

\# The University of the Faroe Islands, Noatun, FO-100, Tórshavn, Faroe Islands

Woods Hole Oceanographic Institution, Woods Hole, Massachusetts 02543, USA

Convective vertical mixing in restricted areas of the subpolar oceans, such as the Greenland Sea, is thought to be the process responsible for forming much of the dense water of the ocean interior $^{1,2}$. Deep-water formation varies substantially on annual and decadal timescales ${ }^{3-5}$, and responds to regional climate signals such as the North Atlantic Oscillation ${ }^{6,7}$; its variations may therefore give early warning of changes in the thermohaline circulation that may accompany climate change ${ }^{8}$. Here we report direct measurements of vertical mixing, by convection and by turbulence, from a sulphur hexafluoride tracer-release experiment in the central Greenland Sea gyre. In summer, we found rapid turbulent vertical mixing of about $1.1 \mathrm{~cm}^{2} \mathrm{~s}^{-1}$. In the following late winter, part of the water column was mixed more vigorously by convection, indicated by the rising and vertical redistribution of the tracer patch in the centre of the gyre. At the same time, mixing outside the gyre centre was only slightly greater than in summer. The results suggest that about $10 \%$ of the water in the gyre centre was vertically transported in convective plumes, which reached from the surface to, at their deepest, 1,200-1,400 m. Convection was limited to a very restricted area, however, and smaller volumes of water were transported to depth than previously estimated ${ }^{9}$. Our results imply that it may be the rapid year-round turbulent mixing, rather than convection, that dominates vertical mixing in the region as a whole.

The experiment was begun by releasing, in streaks, $320 \mathrm{~kg}$ of sulphur hexafluoride $\left(\mathrm{SF}_{6}\right)$ in the central Greenland Sea during August 1996 (Fig. 1). By continually adjusting the depth of the tracer injection apparatus, the tracer was injected as nearly as possible on a single density surface (potential density referenced to $500 \mathrm{dbar}$, $\sigma_{0.5}=30.4268$, with standard deviation 0.0004 ) near $300 \mathrm{~m}$ depth. This enabled its subsequent spread to be used to accurately measure diapycnal (cross-density) mixing ${ }^{10-12}$. The region is dominated by a cyclonic circulation ${ }^{2}$, steered by the bottom topography, and the resulting upward-doming of the density structure in the centre of the gyre is believed to help "precondition" the water column there to deep convection ${ }^{1,13,14}$, as possibly does brine release into the water during ice formation in winter ${ }^{15}$.

Following the release of the tracer, its distribution was documented in November 1996, February-March 1997 and April-May 1997, the analytical technique used being that described by Law et al. ${ }^{16}$.
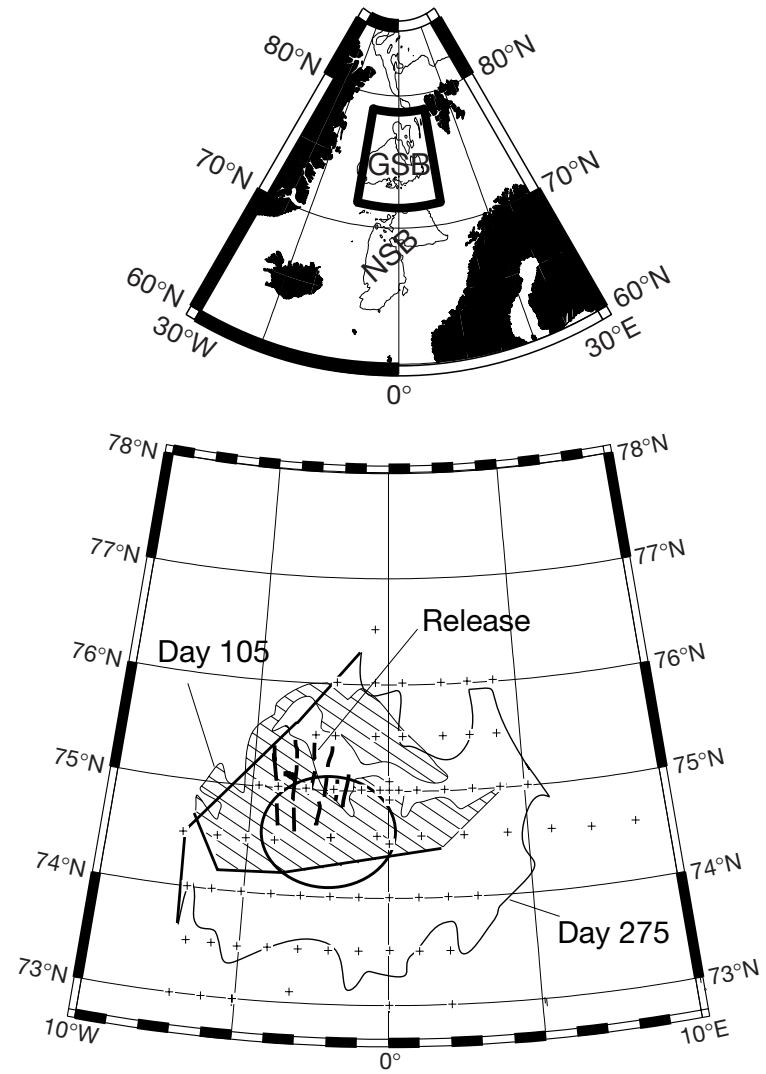

Figure 1 The location of the experiment. The upper map shows the Nordic seas, with the 3,000-m depth contour drawn to delineate the Greenland Sea basin (GSB) and the Norwegian Sea basin (NSB). The region in the box is shown in the lower map. Thick lines show streaks of tracer released in August 1996. Thinner lines show the position of the patch (defined as the region within the $10 \mathrm{nmol} \mathrm{m}^{-2}$ contour of $\mathrm{SF}_{6}$ column integral) found on surveys at about 105 days after release (survey 1; hatched area) and 275 days (survey 3). Thicker edges show where the edge of the tracer patch could not be delineated because of the presence of ice. The ellipse encloses the stations considered as the 'gyre centre'. Crosses show positions of stations during survey 3.

Each survey consisted of more than 50 stations at which the depth distribution of tracer was documented. Representative distributions of the tracer are shown in Fig. 1. Ice conditions were particularly severe in the Greenland Sea during the 1996/1997 winter, and the survey vessel was sometimes unable to delineate the tracer patch to the west and south. Nevertheless, integration of all the samples suggests that on each survey, about $60-70 \%$ of the released tracer was accounted for within the sampled area.

Average tracer-versus-depth profiles for the three surveys are shown in Fig. 2. A correction for background concentrations has been made, based on a pre-release survey of concentrations. Mean vertical profiles could be obtained by simply averaging concentrations with depth in a given region, but in this case station-to-station variations in the vertical structure due to internal waves and sloping isopycnals tend to broaden the averages. For this reason, in Fig. 2 we have instead averaged together profiles using $\sigma_{0.5}$ as a vertical ordinate (see Supplementary Information), and used average density versus depth relations calculated from the same profiles to map these into depth ${ }^{11,17}$. The tracer sank in the water column from survey 1 to survey 2 (see Table 1 for details of survey times), in response to a deepening of the density structure in the survey region, as shown by the arrows in Fig. 2 which indicate the depth of the "target" isopycnal on each survey. On survey 3, after the deep convection period, the peak of the tracer distribution had risen 


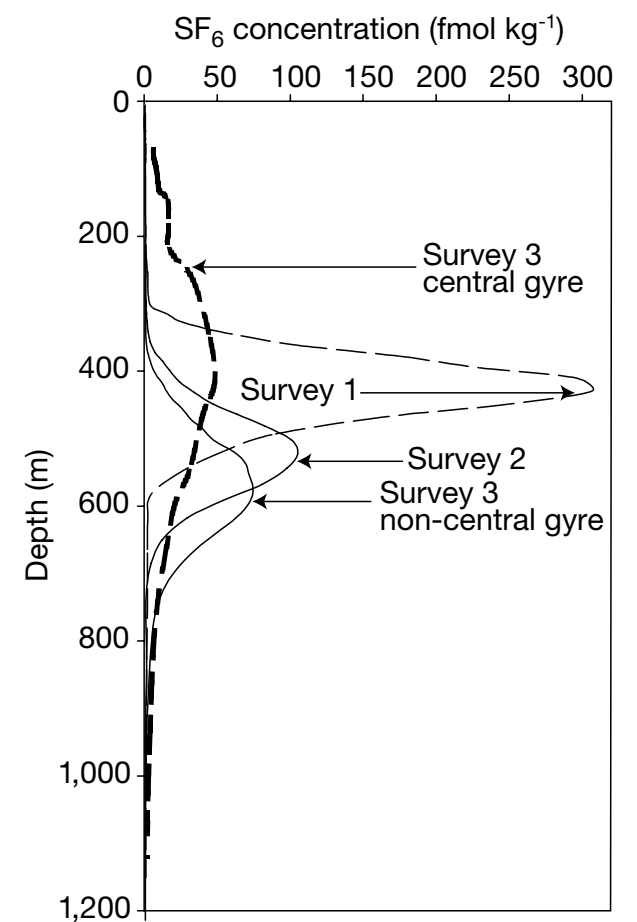

Figure 2 Mean profiles of tracer concentration against depth. Profiles for each of three surveys are shown. For the last survey, the profiles in the centre of the gyre have been plotted separately from those surrounding it. The positions of horizontal arrows show the mean depth at which the potential density corresponding to the tracer release, $\sigma_{0.5}=30.4268 \pm 0.0004$, was found on each survey.

$\sim 150 \mathrm{~m}$ in the gyre centre relative to its depth in the same region on survey 2, and had spread extensively vertically. Outside the gyre centre region, these effects were not apparent.

Table 1 gives the vertical mixing coefficients which would be necessary to produce the observed vertical spreading, assuming one-dimensional turbulent mixing, constant in both time and space, occurring between each pair of surveys. The range of values is calculated from two extreme contrasting assumptions about how the depth-density structure changed: namely, that the structure measured on the initial survey applies to the whole period, or that that on the final survey applies to the whole period ${ }^{17}$. For the summer and early winter at all locations, these estimates are reasonably robust to the different assumptions, and fall in the range $0.66-1.13 \mathrm{~cm}^{2} \mathrm{~s}^{-1}$. In spring outside the gyre the vertical mixing increases somewhat, to $2.1-2.5 \mathrm{~cm}^{2} \mathrm{~s}^{-1}$. In the central gyre post-convection, the stratification had decreased greatly compared to the other surveys, and the mixing rate is not therefore welldefined by this model. The high values, even when calculated using pre-convection depth-density relations, suggest that turbulent exchange was enhanced here, but a more appropriate model is required to interpret the data quantitatively for this period.

From the values in Table 1, we calculate a mean of $1.3 \pm 0.5 \mathrm{~cm}^{2} \mathrm{~s}^{-1}$ for the summer-time, and outside-gyre wintertime, vertical diffusivity. This is substantially larger than the value of $0.12-0.17 \mathrm{~cm}^{2} \mathrm{~s}^{-1}$ found at a similar depth in the subtropical gyre of the North Atlantic by a recent tracer-release experiment ${ }^{12,17}$. However, the hydrography of the two sites is very different, and in particular the stratification as measured by the buoyancy frequency $N$ in the present experiment was $0.3-0.5$ cycles per hour (c.p.h.), compared to $\sim 2.5$ c.p.h. in the subtropical North Atlantic.

Substantial changes in the temperature and salinity distribution in the gyre centre accompany the evolution of the tracer patch between surveys 2 and 3. The inventories of salt and tracer in the a

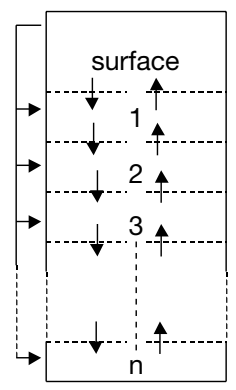

b

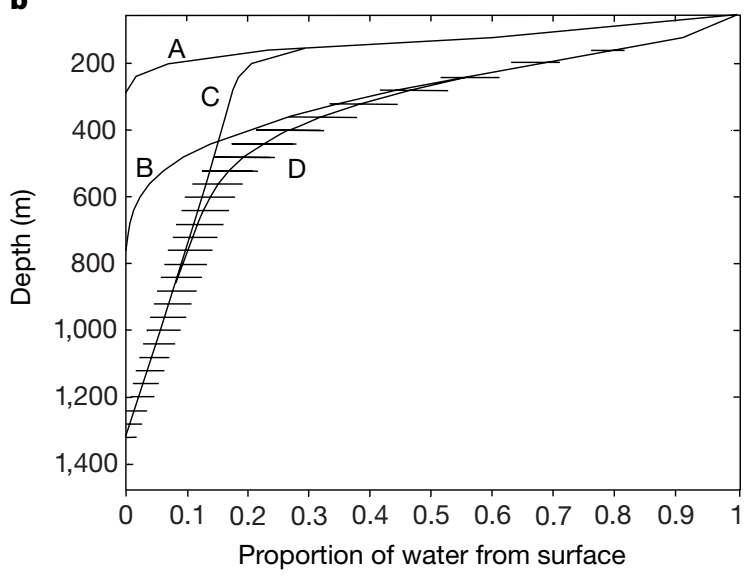

Figure 3 Diagram of the mixing calculation and results. $\mathbf{a}$, Diagram of the onedimensional model for the gyre centre during late winter period. Densification of water at the surface can cause water from the surface box to be transferred to depth in the water column, while vertical turbulent exchange connects adjacent boxes (see Methods for details). $\mathbf{b}$, Proportion of water mixed from the surface to depth by different processes in the scheme of $\mathbf{a}$. Trace A, uniform "background" turbulent mixing $\left(3 \mathrm{~cm}^{2} \mathrm{~s}^{-1}\right)$ only. Trace $B$, enhanced turbulent mixing, rising from $3 \mathrm{~cm}^{2} \mathrm{~s}^{-1}$ at $1,360 \mathrm{~m}$ to $18 \mathrm{~cm}^{2} \mathrm{~s}^{-1}$ at $200 \mathrm{~m}$. Trace C, surface-to-deep transport by deep convection, increasing linearly from zero at $1,360 \mathrm{~m}$ to $20 \%$ at $200 \mathrm{~m}$. Trace D, the sum of traces B and C-the model "best fit" to the temperature, salinity and $\mathrm{SF}_{6}$ data. Error bars show $99 \%$ confidence limits.

gyre centre remain nearly constant but are redistributed vertically, consistent with the idea that changes are due mostly to vertical processes rather than horizontal exchange. We have therefore applied a one-dimensional model, shown in Fig. 3a and described in some detail in the Methods section, to the gyre centre between surveys 2 and 3 . Figure $3 \mathrm{~b}$ shows model results for the amount of water at each depth deriving from the surface at the time of survey 3. Error bars show $99 \%$ confidence levels. Best fits were obtained with deep convection involving $20 \pm 2 \%$ of the water column at $200 \mathrm{~m}$ depth, decreasing linearly to zero at $1,300 \pm 100 \mathrm{~m}$ depth.

The overall effect of convection on vertical mixing during the period August 1996-May 1997 was a modest increase in 'effective mixing' in the gyre centre compared to the surrounding region (Table 1, estimates of $k_{z}$ from release). Because the convection took place over a restricted area $\left(2-4 \times 10^{10} \mathrm{~m}^{2}\right.$, which is $10-20 \%$ of the area of the Greenland Sea) the actual volume of water involved is rather small $\left(2-4 \times 10^{12} \mathrm{~m}^{3}\right)$, and the effect was relatively quickly diluted into the surrounding waters during the following year. Convection was not sufficiently widespread or intense to homogenize the centre of the gyre, so that a pronounced tracer peak remained in the vertical, as well as substantial horizontal inhomogeneities in concentration. The small-scale turbulent vertical mixing, relatively vigorous here compared to other parts of the ocean, thus dominated the vertical redistribution of water properties over the Greenland Sea as a whole. Studies which assume that vertical spreading of tracer properties in the water column is 
Table 1 Coefficients of vertical turbulent exchange

\begin{tabular}{|c|c|c|c|c|}
\hline & $\begin{array}{l}\text { Mean time } \\
\text { from release } \\
\text { (d) }\end{array}$ & $\begin{array}{c}k_{z} \text { from release } \\
\left(\mathrm{cm}^{3} \mathrm{~s}^{-1}\right)\end{array}$ & $\begin{array}{c}k_{z} \text { from survey } 1 \\
\left(\mathrm{~cm}^{3} \mathrm{~s}^{-1}\right)\end{array}$ & $\begin{array}{c}k_{z} \text { from survey } 2 \\
\left(\mathrm{~cm}^{3} \mathrm{~s}^{-1}\right)\end{array}$ \\
\hline Survey 1 & 101 & $1.11-1.14$ & & \\
\hline Survey 2 & 199 & $0.85-1.1 .13$ & $0.66-0.84$ & \\
\hline $\begin{array}{l}\text { Survey } 3 \\
\text { (non-central region) }\end{array}$ & 274 & $1.03-1.35$ & $1.39-1.90$ & $2.16-2.49$ \\
\hline $\begin{array}{l}\text { Survey } 3 \\
\text { (central region) }\end{array}$ & 274 & $1.49-6.03$ & $1.07-7.30$ & $3.46-14.87$ \\
\hline
\end{tabular}

These coefficients $\left(k_{z}\right)$ were calculated from the data in Fig. 2 ; using the relation $2 k_{z} t=s_{2}^{2}-s_{1}^{2}$ where $t$ is the time separating two profiles of second moment $s_{1}^{2}$ and $s_{2}^{2}$. Second moments were found by least-squares fits of gaussian curves to the mean tracer-depth profiles. Profiles were averaged using potential density $\left(\sigma_{0.5}\right)$ as a vertical ordinate. The lower and upper estimates for each rate correspond to the use of the initial and final mean depth-versus-density profile, respectively (see Supplementary Information). Consistent estimates are obtained except, as shown in the last row of the table, in the central gyre over the period during which convection occurs.

dominated by convection may therefore over-estimate its importance. For example, our estimate for the volume of water involved in convection is about an order of magnitude less than that derived by Rhein ${ }^{9}$ from a study of chlorofluorocarbons in the Greenland Sea. Historically, 1996/1997 was a moderately active year for convection; in some of the early years of this decade, convection was confined to within a few hundred metres of the surface, while in the period 1960-80 it is believed to have penetrated to great depth resulting in bottom water renewal ${ }^{18}$. Whereas those active years left a signal in local water-mass properties which persists for decades, the signal due to the moderate convection of $1996 / 1997$ is likely to be quickly erased.

Apart from the measurement of the effects of mixing in the gyre, a second important purpose of the tracer-release experiment is to test alternative hypotheses for the role of the Greenland Sea as a source for deep waters of the North Atlantic ${ }^{19,2}$ and Norwegian Sea Deep Waters ${ }^{20}$. For these reasons, concentrations of $\mathrm{SF}_{6}$ continue to be monitored in the region. As of summer 1998, tracer was undetectable in any of the overflows to the North Atlantic, but tracer had been observed moving into the Norwegian Sea basin, and also spreading northward into the Arctic Ocean via the Fram Strait.

\section{Methods}

\section{One-dimensional model}

This numerical scheme was used to diagnose convection and mixing. Figure $3 \mathrm{a}$ shows the transports included in the calculation. The water column in the central gyre is represented by a stack of interconnected boxes for each of which the average temperature, salinity and tracer concentration are specified at the time of surveys 2 and 3. Vertically integrated changes of heat, salt and tracer content then give the surface exchanges of heat, fresh water, and tracer (though the last is negligible). Heat and fresh water are exchanged only from the uppermost box, but turbulent exchange and convection of dense plumes carrying cold surface water into the interior may cool the deeper boxes. The convected volume is assumed to decrease linearly with depth, reflecting a decrease in number of plumes able to penetrate into the water column with increasing depth. The volume of convecting water as a function of depth is then specified by the volume leaving the first box and the rate of linear decrease with depth, both of which are considered as free parameters. To conserve volume, a compensatory upwelling, increasing towards the surface, is assumed. Convection is assumed also to enhance turbulent diffusion, the enhancement increasing linearly from zero at the maximum depth of convection and its rate of increase being also treated as a free parameter. The equations were initialized with mean profiles from the centre of the gyre on survey 2, and stepped forward to simulate the evolution of the gyre centre up to survey 3. Over many runs, the free parameters were varied over a range of values. The run having the 'best-fit' values of these parameters was determined by minimizing the following $\chi^{2}$ parameter ${ }^{21}$ :

$$
\sum_{j=1}^{3} \sum_{i=2}^{n} \frac{\left(x_{i j}-X_{i j}\right)^{2}}{\sigma_{i j}^{2}}
$$

where $j=1,2,3$ specifies potential temperature, salinity or $\mathrm{SF}_{6}$, and $i=2, \ldots n$ enumerates the levels (below the surface box) in the model, $x_{i j}$ is the model output and $X_{i j}$ the corresponding measurements on survey 3 . The uncertainties $\sigma$ were estimated for potential temperature, salinity and $\mathrm{SF}_{6}$ by calculating the error on the mean of these quantities at each depth in the gyre-centre profiles of survey 3.

Our observations do not tell us at what time between the surveys the convection occurs. The time sequence assumed for the convection has a small influence on the best-fit predictions. For example, if all the convection is assumed to occur in a single burst at the beginning of the modelled period, the heat, salt and tracer transported by the convection would not be identical to the case where the same total amount of water convects to the same depths, but at a uniform rate spread over the entire period. Different assumptions about the timing of convection were tested using heat and moisture fluxes derived for 6-h timesteps from the European Centre for Medium Range Weather Forecast (ECMWF) model. It was assumed that convection was active only when the heat loss rose above some prescribed threshold value. The integrated heat loss over the period from the ECMWF was smaller than that observed in the water column, and the ECMWF heat fluxes were therefore re-scaled to match the observed heat loss. The results shown in Fig. $3 \mathrm{~b}$ are plotted with a threshold value of $380 \mathrm{Wm}^{-2}$, which corresponds to $4.25 \mathrm{~d}$ of convection and cooling of the deeper layers over the 75-d period between the surveys. However, the results were extremely insensitive to the duration of convection; for threshold values between 0 and $500 \mathrm{~W} \mathrm{~m}^{-2}$ (corresponding to 65 to $0.5 \mathrm{~d}$ of convection), the best-fit maximum depth of convection varied $<100 \mathrm{~m}$ and the total amount of water involved varied $<10 \%$.

The model corresponds to the situation in which a population of convective plumes initiated by surface cooling penetrate to various depths, with the number of plumes decreasing as the depth of penetration increases, down to some maximum penetration. Individual plumes have a duration of hours to days onl $\mathrm{y}^{22}$, and contain densified surface water and subsurface water, efficiently mixed ${ }^{23}$, which subsequently spreads out at the resulting density level in the water column. Injection of water to levels at and below the main tracer peak caused the tracer distribution to rise and spread vertically, and these characteristics of the measurements therefore place strong constraints on the total amount of water involved in the convection process and the depths to which it is transported.

Received 25 June; accepted 6 August 1999.

1. Killworth, P. D. Deep convection in the world ocean. Rev. Geophys. Space Phys. 21, 1-21 (1983).

2. Rudels, B. The thermohaline circulation of the Arctic Ocean and the Greenland Sea. Phil. Trans. R. Soc. Lond. A 352, 287-299 (1995)

3. Mosby, H. Deep Water in the Norwegian Sea. Geofis. Publ. 21(3), 1-62 (1959).

4. Schlosser, P., Bönisch, G., Rhein, M. \& Bayer, R. Reduction of deep-water formation in the Greenland Sea during the 1980s—evidence from tracer data. Science 251, 1054-1056 (1991).

5. Meincke, J., Jonsson, J. \& Swift, J. H. Variability of convective conditions in the Greenland Sea. Int. Council Explorat. Seas Mar. Sci. Symp. 195, 32-39 (1992).

6. Dickson, R., Lazier, J., Meincke, J., Rhines, P. \& Swift, J. Long term co-ordinated changes in the convective activity of the North Atlantic. Prog. Oceanogr. 38, 241-295 (1996).

7. Delworth, T. L., Manabe, S. \& Stouffer, R. J. Multidecadal climate variability in the Greenland Sea and surrounding regions: A coupled model simulation. Geophys. Res. Lett. 24, 257-260 (1997).

8. Manabe, S. \& Stouffer, R. J. Century-scale effects of increased atmospheric $\mathrm{CO}_{2}$ on the oceanatmosphere system. Nature 364, 215-218 (1993).

9. Rhein, M. Convection in the Greenland Sea, 1982-1993. J. Geophys. Res. 101, 18183-18192 (1988).

10. Watson, A. J. \& Ledwell, J. R. Purposefully released tracers. Phil. Trans. R. Soc. Lond. A 325, 189-200 (1988).

11. Ledwell, J. R. \& Watson, A. J. The Santa-Monica Basin tracer experiment-a study of diapycnal and isopycnic mixing. J. Geophys. Res. 96, 8695-8718 (1991).

12. Ledwell, J. R., Watson, A. J. \& Law, C. S. Evidence for slow mixing across the pycnocline from an openocean tracer-release experiment. Nature 364, 701-703 (1993).

13. Killworth, P. D. On "chimney" formations in the ocean. J. Phys. Oceangr. 9, 531-554 (1979).

14. Ivey, G. N., Taylor, J. R. \& Coates, M. J. Convectively driven mixed-layer growth in a rotating, stratified fluid. Deep Sea Res. I 42, 331-349 (1995).

15. Visbeck, M., Fischer, J. \& Schott, F. Preconditioning the Greenland Sea for deep convection-ice formation and ice drift. J. Geophys. Res. 100, 18489-18502 (1995).

16. Law, C. S., Watson, A. J. \& Liddicoat, M. I. Automated vacuum analysis of sulfur-hexafluoride in seawater-derivation of the atmospheric trend (1970-1993) and potential as a transient tracer. Mar. Chem. 48, 57-69 (1994).

17. Ledwell, J. R., Watson, A. J. \& Law, C. S. Mixing of a tracer in the pycnocline. J. Geophys. Res. 103, 21499-22529 (1998)

18. Bönisch, G., Blindheim, J., Bullister, J. L., Schlosser, P. \& Wallace, D. W. R. Long-term trends of temperature, salinity, density, and transient tracers in the central Greenland Sea. J. Geophys. Res. 102, 18553-18571 (1997).

19. Mauritzen, C. Production of dense overflow waters feeding the North-Atlantic across the GreenlandScotland Ridge. 1. Evidence for a revised circulation scheme. Deep Sea Res. I 43, 769-806 (1996).

20. Aagaard, K., Fahrbach, E., Meincke, J. \& Swift, J. H. Saline outflow from the Arctic-Ocean-its contribution to the deep waters of the Greenland, Norwegian, and Iceland Seas. J. Geophys. Res. 96, 20433-20441 (1991)

21. Bevington, P. R. \& Robinson, K. Data Reduction and Error Analysis for the Physical Sciences (McGrawHill, New York, 1992)

22. Klinger, B. A., Marshall, J. \& Send, U. Representation of convective plumes by vertical adjustment. J. Geophys. Res. 101, 18175-18182 (1996).

23. Send, U. \& Marshall, J. Integral effects of deep convection. J. Phys. Oceangr. 25, 855-872 (1995).

Supplementary information is available on Nature's World-Wide Web site (http:// www.nature.com) or as paper copy from the London editorial office of Nature.

\section{Acknowledgements}

We thank the staff of RV Håkon Mosby, RV Johann Hjort and RRS James Clark Ross for their support, and B. Guest, S. C. Sutherland, M. I. Liddicoat, R. D. Ling and T. Fileman for assistance. The main support for this work was from the EU MAST-III programme, European sub-polar ocean project, phase 2. Additional support from the following national agencies was also important: NERC (UK) NRC (Norway) and NSF (USA).

Correspondence and requests for materials should be addressed to A.J.W (e-mail: a.watson@uea.ac.uk). 